\title{
In Memoriam Dietrich Hoffmann
}

\author{
by \\ Hubert Klus ${ }^{1}$, Michael Kunze ${ }^{2}$, and the Editors of "Beiträge zur Tabakforschung International" \\ ${ }^{1}$ Oriongasse 9, 3100 St. Pölten, Austria \\ ${ }^{2}$ Institut für Sozialmedizin der Medizinischen Universität Wien, Rooseveltplatz 4, 1090 Wien, Austria
}

Dietrich Hoffmann passed away on April 20, 2011, at his home in Larchmont, New York. He had suffered from Parkinson's disease for more than 20 years. With Dietrich Hoffmann's death the tobacco community lost one of its most prominent scientists, who was familiar with all areas of tobacco research. His work guided and influenced a whole generation of scientists working in the tobacco industry, universities, regulatory agencies, national governments or international organizations, such as the World Health Organization and the International Agency for Research on Cancer (IARC). It is an obligation of honor for the authors M. Kunze, H. Klus, and the editors of Beiträge zur Tabakforschung International to publish a short tribute in memory of Dietrich Hoffmann.

Dietrich Hoffmann was born in Danzig (then a Free City, now Poland) on December 10, 1924. After World War II he studied at the University of Kiel earning a diploma in Chemistry. He joined the Max Planck Institute for Biochemistry in Tübingen and Munich and earned his doctoral degree (Dr. rer. nat.) in 1957 under the supervision of the Nobel Laureate, Professor Dr Adolf Butenandt. The parts of the thesis concerning 1,4-oxazines were published later with his colleague, Dr E. Biekert (1-3). Made possible by the exchange program for young graduated scientists between the United States and Europe Dietrich Hoffmann became a grantee at the Memorial Sloan-Kettering Cancer Center in New York in 1957, where he joined the epidemiologist and cancer prevention pioneer, Ernest L. Wynder. This was the beginning of a personal friendship and a scientifically very productive partnership in environmental cancer research, which lasted for all the years until Ernest Wynder's death in 1999.

Wynder left the Sloan-Kettering Institute in 1969 and founded the American Health Foundation (AHF) in Valhalla, New York. Dietrich Hoffmann followed him. He was Chief of the Division of Environmental Carcinogenesis and served also as Associate Director at the AHF's Naylor Dana Institute for Disease Prevention from 1980 to 1995. In 1995, the AHF became the Institute for Cancer Prevention (IFCP) and Dietrich Hoffmann continued his work as a member of the Division of Cancer Etiology and Preven- tion until 2004, when the IFCP was closed.

When Dietrich Hoffmann came to the United States, the subject of his work was to study carcinogenic compounds in air. By 1963, air pollution by industry and automobile exhausts had become an important issue. Because of his research involvement Dietrich Hoffmann's residence permit was extended and he became a U.S. citizen in May 1967. Dietrich Hoffmann was married in 1960. Together with his wife, Ilse, he published several papers on changes in cigarette design and their influence on the health risks for smokers - a research field of major importance from the early 1950s on. The trigger for these changes were the epidemiological studies by WYNDER and GRAHAM, demonstrating that cigarette smoking was a possible etiologic factor in bronchiogenic carcinoma - published in the Journal of the American Medical Association in 1950 (4) and the 1964 report to the U.S. Surgeon General "Smoking and Health" - the so-called Terry Report (5). The changes in cigarette design were strongly influenced by Dietrich Hoffmann's work at the Naylor Dana Institute in Valhalla. Dietrich Hoffmann's colleague, Ernest L. Wynder, was an advocate of "less harmful" tobacco consumption, especially of reducing the health risks of cigarette smoking. Therefore, Dietrich Hoffmann also became deeply involved in this subject. He and his group identified several carcinogenic compounds in tobacco smoke, searched for their precursors in tobacco and made suggestions for reducing them and, consequently, for reducing specific carcinogenic compounds in tobacco and tobacco smoke. For example, in 1975, at the $3^{\text {rd }}$ World Conference on Smoking and Health in New York on the topic of "Modifying the Risk for the Smoker" Dietrich Hoffmann was the author or co-author of several notable presentations. Less harmful tobacco products were the subject of several Banbury Conferences in Cold Spring Harbor, where major contributions were made by Dietrich Hoffmann. The way of thinking and reasoning of many scientists working for the tobacco industry and in government agencies or universities was strongly influenced and guided by the relevant publications of Dietrich Hoffmann. 
Dietrich Hoffmann made more than 500 contributions to the scientific literature as primary investigator, co-author or editor. Looking at his publication list he investigated and published on different areas of chemical carcinogenesis, the effects of air pollution and diet on cancer and, last but not least, on the composition of tobacco and tobacco smoke, focusing on the compounds assumed to be responsible for health problems in smokers and non-smokers. He studied polycyclic aromatic hydrocarbons, nitrogen containing aromatic compounds, such as aza-arenes and aromatic amines (amino-naphthalenes), phenols, carbonyls, chlorinated pesticides used in tobacco cultivation, volatile $N$ nitrosamines and tobacco specific $N$-nitrosamines (TSNAs). As the presence of the polycyclic aromatic hydrocarbon, benzo $[a]$ pyrene, in tobacco smoke was disputed by some scientists in the 1950s, he isolated this carcinogenic compound in solid form from cigarette mainstream smoke by paper chromatography and purified it by high-vacuum sublimation and recrystallization. The purity of the substance obtained was established by melting point and mixture melting point (6). Dietrich Hoffmann was the first to demonstrate that the tobacco specific $N$ nitrosamine, $N$-nitrosonornicotine ( $\mathrm{NNN}$ ), was not only formed from the minor tobacco alkaloid, nornicotine, but also from nicotine $(7,8)$. Later, he identified 4-(methylnitrosamine)-1-(3-pyridyl)-1-butanone (NNK) as another carcinogenic TSNA, generated exclusively from nicotine. A direct impact of his research work is also seen on tobacco: Dietrich Hoffmann detected the presence of $N$ nitrosodiethanolamine in tobacco and tobacco smoke (9). He showed that this nitrosamine was an animal carcinogen in Syrian Golden Hamsters and possibly also for humans (10). The source of $N$-nitrosodiethanolamine in tobacco products was the diethanolamine used in the sucker control formulation, maleic hydrazide (MH-30). Due to the findings of Dietrich Hoffmann diethanolamine was replaced by potassium in the MH-30 formulation and, consequently, $N$ nitrosodiethanolamine was no longer found in tobacco products. This was confirmed by BRUNNEMANN and HOFFMANN in 1991 (12).

He also studied the mutagenicity and carcinogenicity of gasoline and diesel engine exhaust and other environmental pollutants. Accordingly, air pollution by tobacco smoke components was also a topic of his scientific activities. In his research, he combined his excellent knowledge of modern analytical techniques with biological in-vitro and in-vivo assays.

Dietrich Hoffmann served as an advisor and expert to various U.S. Surgeon General's Advisory Committees on the Health Consequences of Tobacco, the Canadian Advisory Committees on Involuntary Smoking and on Reduction of Cigarette Smoke Toxicity, the U.S. National Cancer Institute, the International Agency for Research on Cancer (IARC, Lyon, France) and the World Health Organization's (WHO) Study Group on Smokeless Tobacco. This way, Dietrich Hoffmann exerted a major influence on the tobacco industry worldwide and on national and international health authorities.

His research achievements were recognized by many organizations, such as the U.S. National Academy of Sciences and the Cosmetic Ingredients Review Panel of the Cosmetics, Toiletries and Fragrance Association in 1993.
He received the 1994 Westchester County Distinguished Chemist Award of the American Chemical Society, the Alton Ochsner Award Relating Smoking and Health (shared with Steve Hecht) in 2001 and the Tobacco Science Research Conference Lifetime Achievement Award in 2004. The latter award was given to Dietrich Hoffmann for his important contributions to tobacco science over so many years. It demonstrated the esteem for Dietrich Hoffmann felt by the scientists of the tobacco industry (11). Dietrich Hoffmann was a regular Tobacco Chemists' Research Conference (TCRC) participant since 1966. He authored or co-authored more than 100 TCRC presentations. He also participated in several CORESTA Congresses, were H.K. met him for the first time in 1974 in Montreux, Switzerland.

Dietrich Hoffmann was a member of the American Association for Cancer Research and of the American Chemical Society, a fellow of the American Chemical Institute, a member of the American Society for Preventive Oncology, the Gesellschaft Deutscher Chemiker (German Chemists' Association), the New York Academy of Sciences, the Phytochemical Society of America, the Society of Toxicology and the Society for Research on Nicotine and Tobacco. He enjoyed the honor of being a member and Past President of St. Matthew's Lutheran Church in White Plains, New York, and of the Steuben Society of American and its National Council.

Dietrich Hoffmann is survived by his wife of 51 years, Ilse, two sons and one grandson.

The contributions and the importance of Dietrich Hoffmann for the science of carcinogenicity caused by lifestyle and environmental factors are impressively documented in the list of his publications. It is published in this issue of "Beiträge zur Tabakforschung International" as a last "thank you"!

\section{ACKNOWLEDGMENTS}

The contents of this tribute are based on public sources, an obituary circulated by Dietrich Hoffmann's family, private information obtained from Ilse Hoffmann and our personal experience.

\section{REFERENCES}

1. Biekert, E., D. Hoffmann, and L. Enslein: Über 1,4Oxazine. IV. Kondensation von 1, 2-Amino-alkoholen mit $\alpha$-Ketocarbonsäure-estern zu 5.6-Dihydro-1.4oxazinonen-(2); Chem. Ber. 94 (1961) 2778-2785.

2. Biekert, E., D. Hoffmann, and F.J. Meyer: Über 1.4Oxazine. I. Darstellung kondensierter 1.4-Oxazinone(2) durch Umsetzung von $o$-Aminophenolen mit $\alpha$ Ketoestern; Chem. Ber. 94 (1961) 1664-1675.

3. Biekert, E., D. Hoffmann, and F.J. Meyer: Über 1.4Oxazine. II. Überführung der 1.4-Benzoxazinone-(2) in Phenmorpholone-(2) und $\mathrm{N}$-substituierte Aminoalkohole; Chem. Ber. 94 (1961) 1676-1682.

4. Wynder, E.L. and E.A. Graham: Tobacco smoking as a possible etiologic factor in bronchiogenic carcinoma: a study of 684 proved cases; J. Am. Med. Assoc. 143 
(1950) 329-336.

5. Smoking and Health. Report of the Advisory Committee to the Surgeon General of the Public Health Service. U.S. Department of Health, Education, and Welfare; Washington, D.C. (1964); Publication 1103.

6. Wynder, E.L. and D. Hoffmann: A study of tobacco carcinogenesis, VII. The role of higher polycylic hydrocarbons; Cancer 12 (1959) 1079-1086.

7. Rathkamp, D., D. Chao, and D. Hoffmann: Analytical studies on nonvolatile $N$-nitrosamines in cigarette smoke; $27^{\text {th }}$ Tobacco Chemists' Research Conference, Winston Salem, NC, 1973, No. 26.

8. Hoffmann, D., S.S. Hecht, R.M. Ornaf, and E.L. Wynder: [Chemical Studies on Tobacco Smoke. XXX.] $N^{\prime}$ Nitrosonornicotine in tobacco; Science 186 (1974) 265-267.

9. Brunnemann, K. D. and D. Hoffmann: Chemical Studies on Tobacco Smoke, LXIX. Assessment of the carcinogenic $N$-nitrosodiethanolamine in tobacco products and tobacco smoke; Carcinogenesis 2 (1981) 1123-1127.

10. Hilfrich, J., I. Schmeltz, and D. Hoffmann: [A study of tobacco carcinogenesis, XVII.] Effects of $N$-nitrosodiethanolamine and 1,1-diethanolhydrazine in Syrian golden hamsters; Cancer Lett. 4 (1978) 55-60.

11. Rodgman, A: Dr Dietrich Hoffmann, Recipient of the 2004 Tobacco Science Research Conference Lifetime Achievement Award; Beitr. Tabakforsch. Int. 21 (2005) 254-257.

12. Brunnemann, K.D. and D. Hoffmann: [Chemical Studies on Tobacco Smoke, XC.] Decreased concentrations of $N$-nitrosodiethanolamine and of $N$-nitrosomorpholine in commercial tobacco products; J. Agric. Food Chem. 39 (1991) 207-208.

Corresponding author:

Hubert Klus

Oriongasse 9

3100 St. Pölten, Austria

E-mail:hubert.klus@aon.at 